JONATHAS LIMA SOLER

INSTRUMENTOS JURÍDICOS PARA A MITIGAÇÃO DOS IMPACTOS SOCIOECONÔMICOS DA ATIVIDADE MINERÁRIA

Dissertação de Mestrado

Orientador: Professor Titular Dr. Gilberto Bercovici

UNIVERSIDADE DE SÃO PAULO

FACULDADE DE DIREITO

SÃO PAULO - SP

2016 
JONATHAS LIMA SOLER

\section{INSTRUMENTOS JURÍDICOS PARA A MITIGAÇÃO DOS IMPACTOS SOCIOECONÔMICOS DA ATIVIDADE MINERÁRIA}

Dissertação apresentada à Banca Examinadora do Programa de Pós-Graduação em Direito, da Faculdade de Direito da Universidade de São Paulo, como exigência parcial para obtenção do título de Mestre em Direito, na área de concentração de Direito Econômico, sob orientação do Professor Titular Dr. Gilberto Bercovici.

UNIVERSIDADE DE SÃO PAULO

FACULDADE DE DIREITO

SÃO PAULO - SP

2016 
Autorizo a reprodução e divulgação total ou parcial deste trabalho, por qualquer meio convencional ou eletrônico, para fins de estudo e pesquisa, desde que citada a fonte.

\author{
Catalogação da Publicação
}

Serviço de Biblioteca e Documentação

Faculdade de Direito da Universidade de São Paulo

Soler, Jonathas Lima

Instrumentos Jurídicos para a Mitigação dos Impactos Socioeconômicos da Atividade Minerária / Jonathas Lima Soler ; orientador Prof. Titular Dr. Gilberto Bercovici -- São Paulo, 2016.

143.

Dissertação (Mestrado - Programa de Pós-Graduação em Direito Direito Econômico, Financeiro e Tributário) - Faculdade de Direito, Universidade de São Paulo, 2016.

1. Direito - Recursos Minerais. 2. Desenvolvimento econômico. 3. Impactos socioeconômicos da mineração. I. Bercovici, Prof. Titular Dr. Gilberto, orient. II. Título. 
Nome: SOLER, Jonathas Lima.

Título: Instrumentos jurídicos para a mitigação dos impactos socioeconômicos da atividade minerária.

Dissertação apresentada à Banca Examinadora do Programa de PósGraduação em Direito, da Faculdade de Direito da Universidade de São Paulo, como exigência parcial para obtenção do título de Mestre em Direito, na área de concentração de Direito Econômico, sob orientação do Professor Titular Dr. Gilberto Bercovici.

Aprovado em:

Banca Examinadora

\begin{tabular}{|l|l|}
\hline Prof. Dr. & \\
\hline Instituição & \\
\hline Julgamento & \\
\hline Assinatura & \\
\hline Prof. Dr. & \\
\hline Instituição & \\
\hline Julgamento & \\
\hline Assinatura & \\
\hline Prof. Dr. & \\
\hline Instituição & \\
\hline Julgamento & \\
\hline
\end{tabular}


Às mulheres da minha vida, CAROLINA, NICE, MARGARIDA (in memoriam) e MARIA.

Aos homens que me deram e me dão base, LuIS, SEBASTIÃo e ANTONIO (in memoriam). 


\section{AGRADECIMENTOS}

Agradecer as pessoas que tanto me apoiaram nesse momento de vida foi uma das tarefas mais difíceis dessa dissertação.

Pensando sobre o assunto, lembrei-me de um filme indiano, chamado Slumdog Millionaire. A película conta a história de um jovem muito pobre que é sorteado para participar de um programa de televisão que desafia os participantes com uma série de perguntas de conhecimento geral, e que premia m uma quantia milionária aquele que acerta toda a série de questões. Fato é que o protagonista acerta todas as perguntas, despertando a suspeita de fraude por parte dos produtores do programa. O filme então se desenvolve mostrando como o protagonista soube responder a todas as perguntas que lhe foram feitas. Em suma, o conhecimento amplo do personagem se baseava nas experiências e pessoas que participaram da sua vida.

E é exatamente essa a sensação que eu tenho ao concluir essa dissertação. Parece-me que as experiências e personagens da minha vida me trouxeram até esse momento. Fizeram parte de cada pedaço dessa dissertação, do tema à redação final. Foram inúmeras as pessoas e infinitos os momentos que impactaram a construção do homem que eu sou hoje e do texto que ora apresento. Porém, alguns, certamente se destacaram.

Devo agradecer, sem qualquer dúvida, ao SENHOR, pois sem Ele nada seria possível.

Agradeço imensamente à minha família. Os meus pais, NICE e LuIS, mostraram que a felicidade é a única medida do sucesso, acreditaram em mim sempre, e nunca economizaram um centavo que fosse para que eu pudesse usufruir da melhor educação que poderiam me dar, nem que para isso abdicassem de suas vontades pessoais. Amo muito vocês e estou convicto que jamais conseguirei retribuir o que fizeram e fazem por mim. Também tive a sorte de ter os melhores avós do mundo, que me permitiram ser um neto muito feliz e bem nutrido.

Tenho dívida também com professores queridos que me inspiram. Desde os tempos de colégio, Marcio BertTi e Maria CeCiLia TuOn, que me mostraram que o coração fica do lado esquerdo do peito. No Largo São Francisco, tive o prazer de ter assistido as aulas e 
conquistado a amizade da PROF. MARIÂNGEla MAGALHÃEs GOMES, a quem sou muito grato especialmente por compartilhar comigo sua paixão pela academia.

Também sou extremamente grato com alguns amigos, que sem dúvida sentiram minha ausência nessa fase de estudo: Silvia BABOIN, com quem eu tenho a alegria de conviver desde os meus três anos de idade e quem eu adotei como minha irmã mais nova; ANA MARIA Rosa, com quem dividi e divido uma infinidade de xícaras de café; RoDRIGO GRUPPI e ANNA MARIN, meus fiéis escudeiros; e RAPHAEL YUKIO e KARINA SHIROMA, que me lembram repetidamente que tudo vai dar certo. Também não posso deixar de mencionar MARIA VALÉRIA, por escutar minhas ansiedades e aflições; PRISCILA LUCENTI, outra irmã que este filho único acabou por adotar; ANDRÉ LUCENTI e EDUARDO CARVALHO, que sempre me incentivaram a ser alguém maior do que eu me via; RICARDO BLANCO, que me ensinou que para seguir em frente, não se pode olhar para os lados; e, sem dúvida, KIM MODOLO Diz, um parceiro verdadeiro, em quem posso confiar sem medo. O apoio de JULIANO BATTELLA e ANDRÉ JACQUES UCHÔA também foram muito importantes ao longo do Mestrado, e aqui expresso minha gratidão.

Sem dúvida, devo confessar minha dívida com o Prof. GILBERTo BerCOVICI. Mais do que meu orientador, o PROF. BERCOVICI se tornou um grande amigo. Professor, obrigado pela oportunidade, pelos almoços, sugestões, cobranças e risadas. É um exemplo para mim - e acho que não há nada mais importante para um educador do que ser considerado um exemplo pelo seu pupilo. Sou muito grato todos os dias por ter essa oportunidade de aprender com o melhor.

Agradeço também à minha outra metade, CAROLINA (simplesmente: Carolina), por quem sou apaixonado e que sentiu tanto minha ausência durante a concretização desse meu sonho. Não há palavras para descrever o seu apoio incondicional a esse projeto. Você é meu porto seguro e tenho certeza que poderei navegar por mares desconhecidos com tranquilidade, desde que eu tenha o seu sorriso ao meu lado. Te amo infinito! 
Em busca de trabalho e de fortuna descia do norte, subia do sul para o novo eldorado uma vária e sôfrega humanidade: trabalhadores, criminosos,

aventureiros, mulheres da vida, advogados, missionários dispostos a converter gentios. Chegam também do outro lado do mar: árabes e judeus, italianos, suíços e alemães, não esquecendo os ingleses da estrada de ferro Ilhéus-Conquista [...].

Tropas de burro transportavam o cacau seco das fazendas para as estações da estrada de ferro ou para Ilhéus ou Itabuna onde se encontravam as sedes das firmas exportadoras pertencentes a suíços e alemães.

(JORGE AmAdo. Tocaia Grande: a face obscura) 


\section{RESUMO}

SOLER, JONATHAS LIMA. Instrumentos jurídicos para a mitigação dos impactos socioeconômicos da atividade minerária. 2016. 143 fls. Dissertação (Mestrado). Faculdade de Direito, Universidade de São Paulo, São Paulo.

Esta dissertação busca identificar e analisar criticamente os principais instrumentos jurídicos que, na experiência nacional e internacional, podem ser eficazes na mitigação dos impactos socioeconômicos da atividade minerária de larga escala conduzida em locais isolados. Para tanto, elabora-se e apresenta-se um necessário panorama sobre o minério e sobre a atividade minerária, delineando suas principais características, evolução histórica, dados da exploração no Brasil contemporâneo e a regulamentação que é então vigente. Em uma segunda parte, a partir de uma visão jurídica, abordam-se os principais tipos de impactos socioeconômicos identificados pela literatura nacional e internacional. Por fim, expõe-se uma análise sobre os instrumentos jurídicos mais eficazes para combater tais impactos, com base na pesquisa desenvolvida. Ao longo do texto, introduzimos e desenvolvemos o conceito de neoextrativismo, que ainda é pouco explorado na literatura jurídica, e que garante ferramentas teóricas para (i) se compreender a relação entre Estado, comunidade e mineradoras em países em desenvolvimento, como o Brasil, e (ii) analisar criticamente tanto os impactos da mineração quanto os instrumentos jurídicos que são aqui abordados.

Palavras-chave: Mineração, Desenvolvimento, Direito dos Recursos Minerais, Impactos Socioeconômicos, Neoextrativismo. 


\begin{abstract}
SOLER, JONATHAS LIMA. Legal instruments able to mitigate socioeconomic impacts of the mining activity. 2016. 143 fls. Dissertação (Mestrado). Faculdade de Direito, Universidade de São Paulo, São Paulo.
\end{abstract}

This thesis aims to identify and critically analyze the main legal instruments that, in the national and international experience, may be able to mitigate socioeconomic impacts caused by large-scale mining conducted in isolated areas. For these purposes, we prepare and present an overview about ore and mining activity, outlining their main features, historical evolution, data regarding mining exploitation in Brazil, and current regulation. In a second part, the thesis approaches, from a legal viewpoint, the main types of socioeconomic impacts identified according to national and international literature. Finally, the thesis presents an analysis on the legal instruments most able to mitigate the aforementioned impacts, based on the research we conducted. Throughout the text, we introduce and elaborate on the concept of neoextractivism, which is still little explored in legal literature, and provides theoretical tools to (i) understand the relationship among State, community, and mining companies in developing countries, such as Brazil; and (ii) critically analyze both the mining impacts and the legal instruments that are addressed herein.

Key-words: Mining, Development, Mineral Resources Law, Socioeconomic impacts, Neoextractivism 


\section{LISTA DE FIGURAS}

Figura 01: Principais regiões com depósitos minerais 50

Figura 02: Mapa de conflitos relacionados à atividade minerária na América Latina

\section{LISTA DE GRÁFICOS}

Gráfico 01: Consumo de metais no mundo

Gráfico 02: Exportações de minério de ferro pelo Brasil.

Gráfico 03: Exportação de minério de ferro do Brasil para a China 45

Gráfico 04: Evolução do preço do minério de ferro no mercado global. 45

Gráfico 05: Investimento estrangeiro direto - indústria extrativa 46

Gráfico 06: Reservas de minério de ferro no mundo 51

Gráfico 07: Remessa de lucros e dividendos - indústria extrativa - minerais metálicos

Gráfico 08: Exportações brasileiras (2014) 54

Gráfico 09: Arrecadação da CFEM no Brasil. 56

Gráfico 10: Participação dos Estados na arrecadação da CFEM em 2015 57

Gráfico 11: Distribuição da CFEM. 62

Gráfico 12: Procedimento para obtenção de concessão de lavra 65

Gráfico 13: Concessões de Lavra outorgadas (2011-2015. 66

Gráfico 14: Alvarás de pesquisa publicados (2011-2015). 67

\section{LISTA DE TABELAS}

Tabela 01: Relação entre impactos negativos e instrumentos de mitigação 133 


\section{SUMÁRIO}

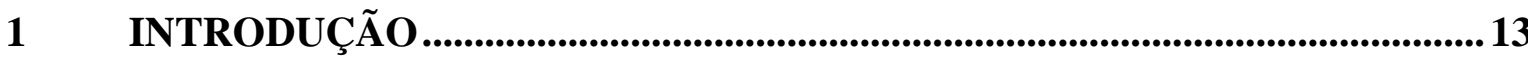

2 CONSIDERAÇÕES ACERCA DA EXPLORAÇÃO DE RECURSOS MINERAIS

3 MINERAÇÃO NO BRASIL: DO COLONIALISMO AO NEOEXTRATIVISMO .....................................................................................32

4 DADOS E NÚMEROS DA MINERAÇÃO NO BRASIL ....................................50

5 REGULAÇÃO DA ATIVIDADE MINERÁRIA NO BRASIL ...........................59

6 OS IMPACTOS SOCIOECONÔMICOS NEGATIVOS DA MINERAÇ̃̃̃O.68

7 OS POSSÍVEIS INSTRUMENTOS JURÍDICOS PARA A MITIGAÇÃO DOS IMPACTOS SOCIOECONÔMICOS DA MINERAÇÃO.....................................99

8 CONSIDERAÇÕES FINAIS ..............................................................................134

9 REFERÊNCIAS BIBLIOGRÁFICAS .......................................................136 


\section{INTRODUÇÃO}

A mineração é uma das atividades econômicas mais antigas praticadas pelo homem ainda que por razões diferentes daquelas que inspiram a atividade minerária contemporânea. Com o avanço da tecnologia e o aumento da população mundial e do mercado consumidor, que demanda mais alimentos e mais produtos industrializados, a importância da mineração cresceu ainda mais.

Hoje, a exploração dos principais recursos minerais utilizados na indústria de transformação, como o minério de ferro, o níquel e o alumínio ocorre em uma escala antes nunca vista. Muito maior do que as metrópoles das antigas colônias já sonharam em conduzir.

No entanto, não devemos nos ofuscar pelo brilho do ouro. A extração dos recursos minerais pode causar certos danos às comunidades que abrigam as minas. ${ }^{1}$ Além dos prejuízos ambientais, que são bastante estudados em diversas áreas do conhecimento (inclusive no Direito), há uma miríade de problemas sociais e econômicos.

Com a instalação de um empreendimento mineiro em determinada região que antes se encontrava, de certa forma, isolada, pautada por uma economia de subsistência ou baseada em trocas comerciais limitadas, há uma ruptura dos padrões sociais e econômicos então estabelecidos.

A instalação de uma mineradora em tais rincões acarreta duas consequências iniciais muito evidentes: a criação de um fluxo migratório para aquele território e a alteração substancial no padrão de ocupação do solo. Essas implicações, por sua vez, são capazes de criar uma infinidade de problemas sociais e econômicos.

As ciências sociais, como demonstraremos adiante no texto, se debruçaram e se debruçam sobre o tema com bastante acerto. Entre as questões pontuadas pelos autores que destacaremos na dissertação, notam-se com bastante clareza: o fenômeno da hiperurbanização; o crescimento desorganizado da área urbana; a perda de áreas antes utilizadas para prática de

\footnotetext{
${ }^{1}$ Em nosso texto, adotamos o conceito de comunidade em sua forma ampla, albergando todos os que sofrem o impacto da mineração, em razão da proximidade com o empreendimento, ainda que em munícipios distintos daquele município no qual se instalou a sede da mineradora. Nesse sentido: "Quanto à Comunidade local, em geral, esta pode ser representada pela população existente no Município-sede da Grande Mina, diretamente vinculada, que é vizinha das terras pertencentes à mina, seja na divisa ou em outros espaços adjacentes. É ainda Comunidade local, a população residente em centros urbanos vizinhos, onde todos experimentam efeitos derivados da atividade da mina, em suas residências, em suas locomoções, seja por se situarem em vias de acesso concorrentes e utilizadas também pela mina ou, por estarem em áreas de influência no acesso à mina, aos escritórios, centros de aprovisionamento. Ou, ainda, na influência da localização de outras quaisquer utilidades e serventias, em uso pela mina, suas contratadas, empreiteiras ou dos seus funcionários" (FERNANDES, Francisco Rego Chaves; LIMA, Maria Helena Rocha; TEIXEIRA, Nilo da Silva. Grandes minas e comunidade: algumas questões conceituais. Série Estudos e Documentos, n.73. Rio de Janeiro: CETEM, 2007, p.28-29).
} 
extrativismo sustentável; a especulação imobiliária; os danos às culturas e tradições locais; o aumento da vulnerabilidade dos moradores e também dos níveis de violência; a ocupação irregular de áreas que deveriam ser protegidas tanto por razões ambientais quanto sociais; o aumento desenfreado da demanda por serviços públicos, como saúde, educação e saneamento básico, que não são supridos satisfatoriamente pelo Estado; a inflação; e a caracterização de um quadro de dependência econômica da atividade minerária que pode destruir completamente aquela comunidade em caso de paralisação ou fim do processo de extração dos recursos minerais, além de afetar a governabilidade dos poderes públicos.

Por óbvio, tais questões deflagram, muitas vezes, conflitos entre as comunidades e as mineradoras. As comunidades não atribuem qualquer legitimidade à mineradora para explorar aquela região, sem que sejam, para tanto, indenizadas pelos danos sociais e econômicos decorrentes da mineração. Muitas vezes, os conflitos envolvem sangue; em todos os casos, os conflitos acarretam custos para os empreendedores, tanto no processo de extração quanto no de escoamento da produção.

A nosso ver, tanto os problemas sociais e econômicos que são causados, direta ou indiretamente, pela atividade minerária, quanto os conflitos devem ser combatidos pela ordem jurídica brasileira, pois, em nenhuma circunstância, esse cenário é albergado pelos valores e objetivos da Constituição Federal. ${ }^{2}$

Dessa forma, ao invés de tratarmos os ditames da nossa Constituição como uma fábula de esopo, deve-se garantir juridicamente que os danos causados pela atividade minerária sejam mitigados, além de encontrar formas para que a comunidade que alberga tais riquezas possa utilizá-las também para o seu próprio desenvolvimento econômico e social.

Nesse sentido, é preciso que o Direito disponha de instrumentos suficientes e eficazes para mitigar ou eliminar, conforme o caso, os impactos socioeconômicos da atividade minerária.

E é exatamente sobre esse ponto que a dissertação discorre: quais seriam os instrumentos jurídicos capazes de mitigar ou eliminar os impactos negativos da mineração de grande escala nas comunidades que albergam tal atividade e ao mesmo tempo garantir um grau de desenvolvimento satisfatório para tais comunidades?

2 Cf. BRASIL. Constituição da República Federativa do Brasil de 1988. Disponível em: <http://www.planalto.gov.br/ccivil_03/constituicao/constituicaocompilado.htm>. Acesso em: 21/11/16. 
Ao analisar o quadro regulatório brasileiro, visualizamos que não há instrumentos jurídicos efetivos e capazes de mitigar tais efeitos. Em tese, os dois documentos que poderiam dar algum suporte à essa tarefa, o Plano de Aproveitamento Econômico (PAE) e o Estudo de Impactos Ambiental e Relatório de Impacto Ambiental (EIA/RIMA), deveriam analisar detidamente os impactos socioeconômicos sofridos pelas comunidades. No entanto, na prática, não há uma análise efetiva sobre essa matéria. Negligencia-se deliberadamente o assunto.

Nesse mesmo sentido, notamos que não há qualquer diretriz jurídica que permita que a riqueza mineral possa ser aplicada no desenvolvimento econômico e social da comunidade e do próprio Brasil, exceto pela ínfima Compensação Financeira pela Exploração de Recursos Minerais (CFEM). Não há qualquer incentivo ao encadeamento entre as atividades de mineração e de beneficiamento do minério, o que se traduz, em palavras muito simples, na perda da oportunidade de aproveitarmos os nossos recursos para alcançarmos o desenvolvimento elencando em nossa Constituição Federal. ${ }^{3}$

Em busca de sugestões de instrumentos jurídicos que se alinham com os objetivos constitucionais, recorremos a textos científicos já produzidos, especialmente na área das ciências sociais, tanto da literatura brasileira quanto estrangeira, que tem maior experiência na mitigação de danos socioeconômicos, como se poderá observar na dissertação ${ }^{4}$.

Para tanto, a partir de uma perspectiva jurídica, buscaremos (i) abordar os impactos socioeconômicos causados pela mineração de grande escala identificados pela literatura especializada e (ii) apontar possíveis instrumentos jurídicos adequados que possam minimizar ou eliminar os danos decorrentes de tais impactos.

Ao aprofundarmos a análise tanto dos impactos quanto dos possíveis instrumentos eficazes para a sua mitigação, notamos que deveríamos partir de um arcabouço teórico histórico. Assim, a dissertação também aborda a perspectiva histórica da atividade minerária, especialmente enquanto praticada no Brasil Colônia. Além disso, para aplacar a ingenuidade que guiou nossos estudos em uma fase preliminar da dissertação, trataremos de um tema que se

\footnotetext{
${ }^{3}$ Nesse sentido: "O aumento da renda de uma comunidade pode resultar de pelo menos três processos diferentes: a) o desenvolvimento econômico: isto é, acumulação do capital e adoção de processos produtivos mais eficientes; b) a exploração de recursos naturais não-renováveis; e c) a realocação dos recursos visando a uma especialização num sistema de divisão internacional do trabalho". (FURTADO, Celso. O mito do desenvolvimento econômico. Rio de Janeiro: Paz e Terra, 1974, p. 99).

${ }^{4}$ Cabe destacar que, aparentemente, o quadro de impactos é analisado por teóricos de outros países há mais tempo do que por pesquisadores das ciências sociais que têm debatido a matéria no Brasil, segundo constatamos em nossas pesquisas bibliográficas. Essa é a razão pela qual não nos deteremos exclusivamente nos impactos observados no Brasil.
} 
alinha ao quadro de exploração contemporâneo: o neoextrativismo - ou como as antigas colônias trocaram suas metrópoles pelas multinacionais.

O texto abrange, portanto, nessa ordem, alguns conceitos essenciais para a compreensão da atividade minerária; o panorama da mineração no Brasil, inclusive com a apresentação do aparato histórico e do conceito de neoextrativismo; a regulação dessa atividade econômica de acordo com nossa ordem jurídica; os impactos socioeconômicos propriamente; e as ferramentas hipotéticas encontradas em nossa pesquisa e que ora propomos como sugestões para mitigar e/ou eliminar os referidos impactos.

Não esperamos que a dissertação seja a panaceia das questões enfrentadas por tantas comunidades no Brasil, como se verá ao longo do texto. Esperamos, no entanto, que sirva como uma contribuição teórica para discussão dos impactos socioeconômicos, também no plano jurídico - estendendo-se além das ciências sociais.

Por fim, cabe aqui ressalvar que não contemplaremos as questões ambientais, indígenas ou relacionadas com a fase posterior ao fechamento da mina. Da mesma forma, não lidaremos com regimes de exploração mineral que não sejam próprios da concessão de lavra; e também não realizamos qualquer pesquisa de campo. 


\section{CONSIDERAÇÕES FINAIS}

Ao longo da sua história, o Brasil se tornou um provedor de commodities, como a soja, a cana e também os recursos minerais. Além de ter se tornado o celeiro do mundo, o Brasil se porta cada vez mais como a mina do mundo, provendo minerais estratégicos para a industrialização, como o minério de ferro.

Nesse sentido, a atividade minerária desempenha um alicerce importante da nossa economia. A mineração, como demonstramos, é uma das atividades que sustentam a balança comercial brasileira e não nos parece que há qualquer plano de se alterar esse caminho.

No entanto, a sua importância econômica não deve ser motivo de comemoração, pois não foi e não é capaz de promover o desenvolvimento econômico que a Constituição Federal defende. A razão para essa lógica pessimista se encontra na lógica neoextrativista que orienta a exploração mineral.

Assim como nos tempos de colônia, grupos multinacionais controlam a maioria dos grandes players da atividade minerária no Brasil. Em conjunto com esse fato, as instituições políticas e jurídicas não dispõem de qualquer aparato que permita ao Brasil se apropriar efetivamente das riquezas extraídas e exportadas.

Não bastasse esse cenário, a exploração dos recursos minerais não se atenta à infinidade de danos que são causados às comunidades que abrigam tais atividades conduzidas em larga escala. Como demonstramos, apesar de os danos ambientais serem minimamente mitigados, pela existência de um aparato de controle e fiscalização, os danos sociais e econômicos não são mitigados adequadamente, justamente em razão da inexistência de um quadro de instituições políticas e jurídicas claro, coeso e eficaz que determine a reparação de tais danos.

Entre os danos sociais e econômicos que colhemos a partir de nossa pesquisa bibliográfica no campo das ciências sociais, destacamos aqueles relacionados com a ocupação do solo; a especulação imobiliária; o déficit no atendimento de serviços públicos; a dependência criada pela comunidade em relação à mineradora, tanto no quadro de empregos, quanto na economia local; e a inflação que passa a assolar tais territórios.

Nessa dissertação, buscamos apresentar uma contribuição jurídica ao estudo de tais impactos e de suas possíveis formas de mitigação.

A nosso ver, a adoção de alguns instrumentos normativos e certas políticas públicas eficazes, conforme o caso concreto, poderiam garantir que as comunidades impactadas pela atividade minerária também partilhassem das riquezas minerais extraídas e fossem protegidas dos danos sociais e econômicos. 
Entre os instrumentos, muitos dos quais encontramos na experiência internacional, apresentamos a constituição de fundos soberanos; a normatização e adoção de acordos celebrados entre comunidade, Estado e mineradora; a obrigatoriedade de auditorias prévias à concessão de financiamentos bancários; reformas no sistema tributário; normatização da CSR; e reformulação do EIA/RIMA para efetivamente abranger tais questões socioeconômicas. Também propusemos a estruturação de políticas públicas de dinamização da economia, de treinamento e capacitação dos governos locais, além de iniciativas de transparência, especialmente quanto ao projeto desenvolvido pela mineradora e a arrecadação tributária respectiva.

Como frisamos na apresentação de tais propostas, este não é um rol milagroso. Para cada situação, um ou mais instrumentos seriam recomendáveis. Exige-se, portanto, uma análise casuística. De todo modo, a disponibilização de tais instrumentos pela nossa ordem jurídica é essencial para que sejam utilizados pelas comunidades, Estado e mineradoras.

Em linha com a utilização de tal ferramental, a nosso ver, sem que a lógica neoextrativista seja abandonada, as propostas aqui feitas serão apenas paliativas, sem alterações estruturais que urgem ser realizadas.

A especialização na exportação de produtos sem qualquer valor agregado, como o minério bruto (ou minimamente beneficiado), em conjunto com a dependência econômica criada em relação aos reais controladores das riquezas e compradores das commodities não nos permite alcançar o desenvolvimento.

A nosso ver, ainda que com a obediência aos instrumentos ora propostos, se a lógica de extração não mudar, nosso país estará privado de se apropriar da própria riqueza mineral e de convertê-la em combustível para a inovação, necessária para se alcançar o desenvolvimento almejado pela Constituição Federal. 


\section{REFERÊNCIAS BIBLIOGRÁFICAS}

ALI, Saleem H. Treasures of the Earth: Need, Greed and Sustainable Future. New Haven: Yale University Press, 2009.

ALVARENGA, Darlan. Vale mantém em 2015 posto de maior exportadora do Brasil. G1 Economia, 11 jan. 2016. Disponível em: <http://g1.globo.com/economia/noticia/2016/01/valemantem-em-2015-posto-de-maior-exportadora-do-brasil-veja-ranking.html.> Acesso em: $22 / 09 / 16$.

AUTY, Richard M; MICKSELL; Raymond F. Sustainable Development in Mineral Economies. Oxford: Clarendon Press, 1998.

BARRETO, Maria Laura. Mineração e desenvolvimento sustentável: desafios para o Brasil. Rio de Janeiro, CETEM, 2001.

BERCOVICI, Gilberto. A questão social, a Constituição de 1988 e os desafios do desenvolvimento. In: SOUZA, Pedro de (Org.). Brasil, sociedade em movimento. São Paulo: Paz e Terra, 2015.

BERCOVICI, Gilberto. Direito econômico do petróleo e dos recursos minerais. São Paulo: Quartier Latin, 2011.

BERCOVICI, Gilberto; MASSONETTO, Luís Fernando. Limites da Regulação: esboço para a crítica metodológica do 'novo direito público da economia'. In: Revista de Direito Público da Economia, Belo Horizonte, 2009.

BOWES-LYON, Léa-Marie; RICHARDS, Jeremy P.; MCGEE, Tara M. Socio-Economic Impacts of the Nanisivik and Polaris Mines, Nunavut. In: RICHARDS, Jeremy (editor). Mining, Society, and a Sustainable World. Canada, Springer Berlin Heidelberg, 2010.

BOXER, Charles. A idade de ouro no Brasil. São Paulo: Companhia Editora Nacional, 1963.

BRASIL. BANCO CENTRAL DO BRASIL. Censo de capitais estrangeiros no país. Resultados. Anos-base: 2010-2014. Disponíveis em: <http://www.bcb.gov.br/Rex/CensoCE/port/resultados_censos.asp?idpai=CAMBIO.> Acesso em: $15 / 09 / 16$.

BRASIL. Constituição da República dos Estados Unidos do Brasil, de 24 de fevereiro de 1891. Disponível em <http://www.planalto.gov.br/ccivil_03/Constituicao/Constituicao91.htm>. Acesso em: 21/11/16.

BRASIL. Decreto n. 1, de 11 de janeiro de 1991 - Regulamenta o pagamento de compensação financeira instituída pela Lei n. 7.990, de 28 de dezembro de 1989. Disponível em <https://www.planalto.gov.br/ccivil_03/decreto/1990-1994/D0001.htm>. Acesso em: 21/11/16.

BRASIL. Decreto n. 24.642, de 10 de julho de 1934 - Código de Minas. Disponível em <http://www.planalto.gov.br/ccivil_03/decreto/1930-1949/D24642.htm>. Acesso em: 21/11/16. 
BRASIL. Decreto-Lei n. 227, de 28 de fevereiro de 1967 - Código de Mineração. Disponível em: 〈http://www.planalto.gov.br/ccivil_03/Decreto-lei/Del0227.htm>. Acesso em: 21/11/16.

BRASIL. DEPARTAMENTO NACIONAL DE PRODUÇÃO MINERAL. Sumário Mineral 2015. Brasília: DNPM, 2016. Disponível em <http://www.dnpm.gov.br/assuntos/economiamineral-2015>. Acesso em: 18/09/16.

BRASIL. Lei Complementar n. 87, de 13 de setembro de 1996 - Lei Kandir. Disponível em <https://www.planalto.gov.br/ccivil_03/Leis/LCP/Lcp87.htm>. Acesso em: 21/11/16.

BRASIL. Lei n. 12.351, de 22 de dez. de 2010. Disponível em: <http://www.planalto.gov.br/ccivil_03/_Ato2007-2010/2010/Lei/L12351.htm>. Acesso em: 23/11/16.

BRASIL. MINISTÉRIO DE MINAS E ENERGIA. Anuário Estatístico do Setor Metalúrgico, 2015 base 2014. Disponível em <https://goo.gl/kp015O.> . Acesso em: 20/08/16.

BRASIL. Resolução CONAMA n. 1, de 23 de janeiro de 1986. Disponível em <http://www.mma.gov.br/port/conama/legiabre.cfm?codlegi=23 >. Acesso em: 21/11/16.

BRASIL. Resolução CONAMA n. 237, de 19 de dezembro de 1997. Disponível em <http://www.mma.gov.br/port/conama/res/res97/res23797.html>. Acesso em: 21/11/16.

BRESSER-PEREIRA, Luiz Carlos. O conceito histórico de desenvolvimento econômico, 2006., p. 9. Disponível em <http://www.bresserpereira.org.br/view.asp?cod=1726>. Acesso em: 21/11/16.

BRITO, Daniel Chaves. Mineração, desenvolvimento e impacto socioambiental: Uma experiência do manganês na Amazônia. Belém: Paper do NAEA, 1995.

CABRAL, Eugênia Rosa; ENRÍQUEZ, Maria Amélia; SANTOS, Dalva Vasconcelos. Canaã dos Carajás - do leite ao cobre: transformações estruturais do município após a implantação de uma grande mina. In: ENRÍQUEZ, Maria Amélia; FERNANDES, Francisco Rego Chaves; ALAMINO, Renata de Carvalho Jimenez (Org.). Recursos minerais \& sustentabilidade territorial: grandes minas. Rio de Janeiro: CETEM, 2011.

CANO, Wilson. Ensaios sobre a formação econômica regional do Brasil. São Paulo: Editora Unicamp, 2002.

CARVALHO, Pedro Sergio Landim et al. Minério de ferro. In: BNDES Setorial: Insumos Básicos. Rio de Janeiro, BNDES, v.39, 2006, p.199. Disponível em 〈https://goo.gl/gmZI4s.> Acesso em: 20/08/16.

CATALANO, Edmundo F. Curso de Derecho Minero, 5ª ed., Buenos Aires: Zavalia, 1999.

CORREAA, Vinícius Moreno de Sousa; CARMO, Roberto Luiz. Impactos socioambientais e demográficos do processo de ocupação da atividade mineradora na região sudeste do Pará nos Censos Demográficos de 1970 a 2000. Encontro Nacional de Estudos Populacionais, 2010, p.5. 
DANE, Anthony. Assessing the socio-economic impacts of mining: case study of the Landau Colliery, South Africa. In: RICHARDS, Jeremy (Editor). Mining, Society, and a Sustainable World. Canada: Springer Berlin Heidelberg, 2010.

DIEESE. Remessa de lucros e dividendos: setores e a dinâmica econômica brasileira. Nota técnica, n.137, jun.2014. Disponível em 〈https://goo.gl/OciJ5d >. Acesso em: 21/09/16.

DRAIBE, Sônia. Rumos e metamorfoses: estado e industrialização no Brasil 1930-1960. Rio de Janeiro: Paz e Terra, 2004.

EGGERT, Roderick G. Sustainable Development in the Mining Industry. In: OTTO, J. M; CORDES, J. (Eds). Sustainable Development and the Future of Mineral Investment. Paris: United Nations Environment Programme, 2000.

ENRÍQUEZ, Maria Amélia. Maldição ou dádiva? Os dilemas do desenvolvimento sustentável a partir de uma base mineira. São Paulo: Signus, 2008.

ENRÍQUEZ, Maria Amélia. Mineração: maldição ou dádiva? Os dilemas do desenvolvimento sustentável a partir de uma base mineira. Tese de Doutorado. Brasília: UNB, 2007.

ENRÍQUEZ, Maria Amélia. Mineração: maldição ou dádiva?, 2010. Disponível em: <https://goo.gl/Ua9b5u $>$. Acesso em: 18/09/16.

ENRÍQUEZ, Maria Amélia; FERNANDES, Francisco Rego Chaves; ALAMINO, Renata de Carvalho Jimenez. A mineração das grandes minas e as dimensões da sustentabilidade. In: CETEM, 2011.

Recursos minerais \& sustentabilidade territorial: grandes minas. Rio de Janeiro:

ENRÍQUEZ, Maria Amélia; LIMA, Maria Helena; TEIXEIRA, Nilo da Silva (Org.). A grande mina e a comunidade: estudo de caso da grande mina de ouro de Crixás em Goiás. Rio de Janeiro: CETEM, 2007.

FERNANDES, Francisco Rego Chaves; ALAMINO, Renata de Carvalho Jimenez; ARAÚJO, Eliane Rocha. Atividade mineradora gera riqueza e impactos negativos nas comunidades e no meio ambiente. In: __ Recursos minerais e comunidade: impactos humanos, socioambientais e econômicos. Rio de Janeiro: CETEM, 2014.

FOLHA DE SÃO PAULO. Vale cria condomínio de luxo em reserva ambiental. São Paulo, 20 de fevereiro de 2005.200 Disponível $<$ http://www1.folha.uol.com.br/fsp/brasil/fc2002200507.htm>. Acesso em: 21/11/16.

FUNDAÇÃO GETÚLIO VARGAS. Indicadores de Belo Monte: um projeto da Câmara Técnica de Monitoramento das Condicionantes do Plano de Desenvolvimento Regional Sustentável do Xingu, São Paulo, FGV, fev. 2016.

FURTADO, Celso. Formação econômica do Brasil, 34ª ed. São Paulo: Cia das Letras, 2007.

FURTADO, Celso. O mito do desenvolvimento econômico. Rio de Janeiro: Paz e Terra, 1974.

GALEANO, Eduardo. As veias abertas da América Latina. Porto Alegre: L\&PM, 2016 
HADDOW, Ken. Consultation, the Way Forward. In: Journal of Energy and Natural Resources Law, n.1, v.31, 2013.

HARRISON, James. Establishing a Meaningful Human Rights due Diligence Process for Corporations: Learning from Experience of Human Rights Impact Assessment. In: Impact Assessment and Project Appraisal, n.31, 2013.

HODGER, R. Anthony. Mining Company Performance and Community Conflict: Moving Beyond a Seeming Paradox. In: Journal of Cleaner Production, n.84, 2014.

HOGAN, Daniel. J. Mobilidade populacional, sustentabilidade ambiental e vulnerabilidade social. In: Revista Brasileira de Estudos de População, v.22, São Paulo, jul.-dez. 2005.

HUMPHREYS, David. The Remaking of the Mining Industry. London: Palgrave, 2015

HUMPHREYS, Macartan; SACHS, Jeffrey D.; STIGLITZ, Joseph E. Escaping the Resource Curse. New York: Columbia University Press, 2007.

HUMPHREYS, Macartan; SANDBU, Martin E. The Political Economy of Natural Resource Funds. In: HUMPHREYS, Macartan; SACHS, Jeffrey D.; STIGLITZ, Joseph E. Escaping the Resource Curse. New York: Columbia University Press, 2007.

HUSTRULID, William A.; KUCHTA, Mark. Open Pit Mine: Planning and Design, $2^{\mathrm{a}}$ ed. Londres: Taylor and Francis, 2006.

ICMM. What are minerals and metals?. Disponível em: <https://www.icmm.com/engb/metals-and-minerals/producing-metals/what-are-minerals-metals->. Acesso em: 06/08/16.

JOYCE; THOMSON. Earning a Social License to Operate: Social Acceptability and Resource Development in Canada. Canadá: CIM, v.93, fev. 2000.

KAMIJYO, Miki. The Equator Principles: Improved Social Responsibility in the Private Finance Sector. In: Sustainable Development Law \& Policy, n.35, 2004

KARL, Terry Lynn. Ensuring Fairness: The Case for a Transparent Fiscal Social Contract. In: HUMPHREYS, Macartan; SACHS, Jeffrey D.; STIGLITZ, Joseph E. (editores). Escaping the resource curse. Nova York: Columbia University Press, 2006.

KITULA, A. G. N. The Environmental and Socio-Economic Impacts of Mining on Local Livelihoods in Tanzania: A Case Study of Geita District. In: Journal of Cleaner Production, Filadélfia, n.14, 2005.

LOUREIRO FILHO, Lair da Silva. Exploração de recursos minerais e desenvolvimento sustentável. In: Revista Forense, v.416, 2012.

MACHADO, Iran. A mineração sob a óptica social. In: LINS, Fernando Antonio Freitas; LOUREIRO, Francisco Eduardo; ALBUQUERQUE, Gildo de Araújo Sá. (Orgs.). A construção do Brasil e da América Latina pela Mineração. Rio de Janeiro: CETEM, 2000.

MAURO, Frédéric. Portugal e o Brasil: A Estrutura Política e Econômica do Império, 15801750. In: BETHELL, Leslie (Org.). História da América Latina: América Latina Colonial, v.1, São Paulo: Edusp, 2012. 
MMDA. Desenvolvimento da Comunidade Local. Acordo de Desenvolvimento Comunitário. MMDA Project.org, 15 de fev. 2013. Disponível em <http://www.mmdaproject.org/?p=2812\&lang=pt-br. $>$ Acesso em: 25/05/15.

MOFFAT, Kieren; ZHANG, Airong. The Paths to Social License to Operate: an Integrative Model Explaining Community Acceptance of Mining. In: Journal of Resources Policy, n.39, mar. 2014.

MONTEIRO, Maurílio Abreu. Mineração industrial na Amazônia e suas implicações para o desenvolvimento regional. In: Novos Cadernos NAEA, v.8, n.1, Belém, UFPA, jun. 2005.

MONTEIRO, Maurílio Abreu; COELHO, Maria Célia Nunes. Mineração e entropia: notas sobre interação com processos de desenvolvimento. In: Novos Cadernos NAEA, v.10, n.1, jun. 2007.

MONTEIRO, Maurílio de Abreu. Amazônia: mineração, tributação e desenvolvimento regional. In: Novos Cadernos NAEA, v.7, n.2, p.179, Belém, 2004.

MONTEIRO, Maurílio de Abreu; TEIXEIRA, Sheila do Socorro Lima. Mineração industrial e a estabilidade de assentamentos rurais no sudeste do Estado do Pará. In: Raízes - Revista de Ciências Sociais e Econômicas, v. 25, 2006.

NAÇÕES UNIDAS. Princípios da Conferência das Nações Unidas sobre Meio Ambiente e Desenvolvimento. Rio de Janeiro, 1992. Disponível em: https://goo.g1/PCP98F. Acesso em: 21/11/16.

NASCIMENTO, Nádia Socorro Fialho. A questão agrária, urbana e ambiental na Amazônia brasileira: notas para o debate. In: Revista Temporalis, Brasília, ano 12, n.24, jul-dez 2012.

NASCIMENTO, Nádia Socorro Fialho. Amazônia e desenvolvimento capitalista: a centralidade da região para a acumulação de capital e a produção de expressões da "questão social”. In: Revista de Políticas Públicas, São Luis, n. especial, ago. 2010.

OCANSEY, Ignitious Tetteh. Mining Impacts on Agricultural Lands and Food Security - Case Study of Towns in and around Kyebi in the Eastern Region of Ghana. Finlândia, 2013, 46 fls, p.6. Dissertação (International Business Management) - Turku University of Applied Sciences. Disponível em: 〈http://goo.gl/V2hvDi>. Acesso em: 10/02/15.

ODUMOSU-AYANU, Ibironke T. Governments, Investors and Local Communities: Analysis of a Multi-actor Investment Contract Framework. In: Melbourne Journal of International Law, n.473, 2014.

PEREIRA, Dayan Rios. Alianças e desdobramentos de políticas para o desenvolvimento local: imbricações na mineração de alumínio em Oriximiná/PA. Tese (Doutorado em Ciências do Desenvolvimento). Belém: Universidade Federal do Pará, 2012.

PEREIRA, Denise de Castro et al. Cenários socioambientais em municípios com mineração: uma experiência extensionista. Trabalho de extensão universitária. Belo Horizonte: PUCMinas, 2012.

PEREIRA, Osny Duarte. Ferro e independência: um desafio à dignidade nacional. Rio de Janeiro: Civilização Brasileira, 1967. 
PICQ, Manuela L. Extrativismo: a pedra no caminho do desenvolvimento. In: SOUZA, Pedro de (Org.). Brasil, sociedade em movimento. São Paulo: Paz e Terra, 2015.

PONTES, Júlio Cesar de; FARIAS, Maria Sallydelandia Sobral de; LIMA, Vera Lucia Antunes. Mineração e seus reflexos socioambientais: estudo de impactos de vizinhança (EIV) causados pelo desmonte de rochas com uso de explosivos. In: Revista Polêm!ca. v.12, n.1, 2013. Disponível em: <http://www.epublicacoes.uerj.br/index.php/polemica/article/view/5277/3873>. Acesso em: 11/10/13.

PORTAL TERRA. Desastre em Mariana é o maior acidente mundial com barragens. 15. Jan. 2016. Disponível em: <https://noticias.terra.com.br/brasil/desastre-em-mariana-e-o-maioracidente-mundial-com-barragens-em-100anos, 874a54e18a812fb7cab2d7532e9c4b72ndnwm3fp.html>. Acesso em: 13/10/16.

PRNO, Jason; SLOCOMBE, Scott D. Exploring the Origins of 'Social License to Operate' in the Mining Sector: Perspectives from Governance and Sustainability Theories. In: Journal of Resources Policy, n.37, 2012.

QUEIROZ, Júlia Mello. Desenvolvimento econômico, inovação e meio ambiente: a busca por uma convergência no debate. In: Cadernos do Desenvolvimento. Rio de Janeiro, v.6, n.9, jul$\operatorname{dez} 2011$.

RAMOS, José Raymundo Andrade. Mineração no Brasil Pós-Colônia. In: LINS, Fernando Antonio de Freitas; LOUREIRO, Francisco Eduardo de Vries Lapido; ALBUQUERQUE, Gildo de Araújo Sá Cavalcanti. Brasil 500 anos: a construção do Brasil e da América Latina pela Mineração. Rio de Janeiro: CETEM, 2000.

REDDY, Gerry; SMYTH, Eddie; STEYN, Michael. Land Access and Resettlement: a Guide to Best Practice. Saltaire: Greenleaf, 2015.

REIS, Cristina Fróes de Borja. Desenvolvimento econômico liderado por recursos naturais: uma revisão teórica e crítica da literatura. In: XVII Encontro Nacional de Economia Política da Sociedade Brasileira de Economia Política, 2012, p. 5. Disponível em $<$ http://sep.org.br/artigos $>$. Acesso em: 21/11/16.

RELATÓRIOS DINÂMICOS. MONITORAMENTO DE INDICADORES. Disponível em: $<$ http://www.relatoriosdinamicos.com.br/portalodm/7-qualidade-de-vida-e-respeito-ao-meioambiente/BRA001015089/parauapebas---pa.> Acesso em: 11/10/16.

REVISTA EXAME. Ranking do setor mineração em 2016. Disponível em: <http://mm.exame.abril.com.br/empresas/filtrar/2016/mineracao/Todos > Acesso em: $02 / 10 / 16$.

RUGGIE, John G. Just Business: Multinational Corporations and Human Rights. New York: W.W \& Norton Company, 2013.

SALOMÃO FILHO, Calixto. Direito concorrencial: as estruturas, $3^{\mathrm{a}}$ ed. São Paulo, : Malheiros, 2007.

SCAFF, Fernando Facury. Royalties do petróleo, minério e energia: aspectos constitucionais, financeiros e tributários. São Paulo: RT, 2014. 
SCHOUERI, Luís Eduardo. Direito Tributário. São Paulo: Saraiva, 2011.

SENGUPTA, M. Environmental Impacts of Mining: Monitoring, Restoration and Control. Londres: Lewis Publishers, 1993.

SLACK, Keith. The Role of Mining in the Economies of Developing Countries: Time for a New Approach. In: RICHARDS, Jeremy (editor). Mining, Society, and a Sustainable World. Canada: Springer Berlin Heidelberg, 2010.

SOLER, Jonathas Lima. Aspectos teóricos sobre os principais desafios à Segurança Alimentar e Nutricional em comunidades afetadas pela atividade minerária de grande escala. In: Revista Fórum de Direito Financeiro e Econômico - RFDFE. Belo Horizonte, ano 4, n.6, set.-fev. 2015.

SOLER, Jonathas Lima. Notas sobre a relação entre o Código de Minas de 1934 e a instalação das indústrias de base no Brasil. In: Revista Fórum de Direito Financeiro e Econômico RFDFE, n. 9, Belo Horizonte, março-agosto/2016.

SPITZ, Karlheinz; TRUDINGER, John. Mining and the Environment: from Ore to Metal. Leiden (Holanda): CRC Press, 2008.

SQUEFF, Gabriel Coelho; DE NEGRI, Fernanda. Produtividade do trabalho e mudança estrutural no Brasil nos anos 2000. In: DE NEGRI, Fernanda; CAVALCANTI, Luiz Ricardo (Orgs.). Produtividade no Brasil: Desempenho e Determinantes, v.1. Brasília: IPEA, 2014.

TÁVORA, Juarez. Regime legal de exploração de nossos recursos minerais. In: Petróleo para o Brasil. Rio de Janeiro: José Olympio, 1955.

THE GUARDIAN. Deep See Mining: the Gold Rush on the Ocean Floor. 8 de Abr. 2014. Disponível em: <https://www.theguardian.com/environment/ng-interactive/2014/apr/08/deepsea-mining-the-gold-rush-on-the-ocean-floor>. Acesso em: 12/07/16.

THORP, Rosemary et. al. Los desafíos de la minería y el petróleo para el desarrollo: Lecciones de África y Latinoamérica. Lima: PUCP, 2014.

TRINDADE, José Raimundo. Mineração e políticas de desenvolvimento local para o município de Parauapebas no Pará. In: ENRÍQUEZ, Maria Amélia; FERNANDES, Francisco Rego Chaves; ALAMINO, Renata de Carvalho Jimenez (Orgs.). Recursos minerais \& sustentabilidade territorial: grandes minas. Rio de Janeiro: CETEM, 2011.

VELTMEYER, Henry; PETRAS, James. Extractive Imperialism in the Americas: Capitalism's New Frontier. Chicago: Haymarket, 2015.

VELTMEYER, Henry; PETRAS, James. The New Extractivism: a Post-Neoliberal Development Model or Imperialism of the Twenty-First Century? Londres: Zed Books, 2014.

VIVACQUA, Attilio. A nova política do sub-solo e o regime legal das minas. Rio de Janeiro, Editora Panamericana, 1942.

WANDERLEY, Luiz Jardim. Movimentos sociais em área de mineração na Amazônia Brasileira. In: E-cadernos CES, v.17, 2012, Rio de Janeiro, UFRJ, p.57. Disponível em: <https://eces.revues.org/1117>. Acesso em: 11/10/16. 
WORLD BANK. Total Natural Resources Rents. Disponível em: $<$ http://data. worldbank.org/indicator/NY.GDP.TOTL.RT.ZS? contextual=default\&end $=2014 \&$ locations=BR\&start=2006\&view=chart.. . Acesso em: 24/09/16.

YAKOVLEVA, Natalia. Corporate Social Responsibility in the Mining Industries. Surrey (UK): Ashgate, 2005.

YANGUAS, Javier Arellano. ¿Minería sin fronteras? Conflicto y desarrollo en regiones mineras de Perú. Lima: IEP, 2011. 